\title{
Mesoporous cerium oxide nanospheres for the visible-light driven photocatalytic degradation of dyes
}

\author{
Subas K. Muduli ${ }^{\ddagger 1}$, Songling Wang ${ }^{\ddagger 2}$, Shi Chen ${ }^{3}$, Chin Fan $\mathrm{Ng}^{3}$, \\ Cheng Hon Alfred Huan ${ }^{3,4}$, Tze Chien Sum ${ }^{* 3,5,6}$ and Han Sen Soo ${ }^{* 1,6}$
}

\section{Letter}

\section{Address:}

${ }^{1}$ Division of Chemistry and Biological Chemistry, School of Physical and Mathematical Sciences, Nanyang Technological University, Singapore 637371, ${ }^{2}$ Department of Chemistry, National University of Singapore, 10 Kent Ridge, Singapore $119260,{ }^{3}$ Division of Physics and Applied Physics, School of Physical and Mathematical Sciences, Nanyang Technological University, Singapore $637371,{ }^{4}$ Institute of High Performance Computing, Agency for Science, Technology and Research, 1 Fusionopolis Way, \#16-16 Connexis, Singapore 138632, ${ }^{5}$ Energy Research Institute @ NTU (ERI@N), 1 CleanTech Loop, Singapore 637141 and ${ }^{6}$ Singapore-Berkeley Research Initiative for Sustainable Energy (SinBeRISE), 1 Create Way, Singapore 138602

Email:

Tze Chien Sum* - tzechien@ntu.edu.sg; Han Sen Soo* -

hansen@ntu.edu.sg

* Corresponding author $\ddagger$ Equal contributors

Keywords:

cerium oxide; dye degradation; mesoporous; photocatalysis; visible light

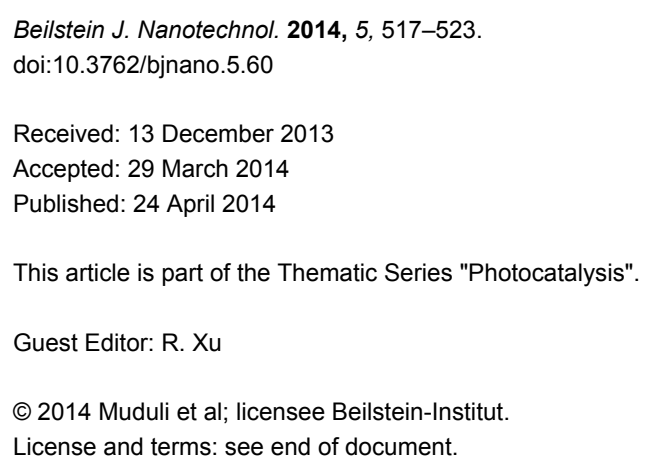

\begin{abstract}
A facile, solvothermal synthesis of mesoporous cerium oxide nanospheres is reported for the purpose of the photocatalytic degradation of organic dyes and future applications in sustainable energy research. The earth-abundant, relatively affordable, mixed valence cerium oxide sample, which consists of predominantly $\mathrm{Ce}_{7} \mathrm{O}_{12}$, has been characterized by powder X-ray diffraction, X-ray photoelectron and UV-vis spectroscopy, and transmission electron microscopy. Together with $\mathrm{N}_{2}$ sorption experiments, the data confirms that the new cerium oxide material is mesoporous and absorbs visible light. The photocatalytic degradation of rhodamin $\mathrm{B}$ is investigated with a series of radical scavengers, suggesting that the mechanism of photocatalytic activity under visible-light irradiation involves predominantly hydroxyl radicals as the active species.
\end{abstract}




\section{Introduction}

The degradation of organic pollutants by affordable and effective chemical methods is an acute problem that has been tackled by advanced oxidation processes [1]. The photocatalytic production of reactive oxygen species by using semiconductor technology has emerged as a sustainable and promising route for such advanced oxidation processes [2-6]. In these photocatalytic processes, based on $\mathrm{TiO}_{2}$ for example, radiation larger than the band gap is absorbed to promote an electron from the valence to the conduction band [2-4]. The resultant strongly oxidizing, valence band holes $\left(h^{+}\right)$and reducing, conduction band electrons $\left(e^{-}\right)$are short-lived under ambient conditions and react with water and air to form reactive oxygen species such as $\cdot \mathrm{OH},{ }^{\bullet} \mathrm{OOH}, \mathrm{H}_{2} \mathrm{O}_{2}$, and $\mathrm{O}_{2}{ }^{-}$for example $[1,2,4-6]$. These reactive oxygen species can subsequently decompose organic pollutants. Recent developments in nanotechnology have enhanced the performance of photocatalytic and solar energy absorption processes by providing higher surface areas and more effective charge separation in semiconductor materials on the nanoscale. In fact, the commercially available Degussa P25 mixed-phase $\mathrm{TiO}_{2}$ is commonly employed as a benchmark in photocatalysis for applications ranging from dye-sensitized solar cells to the oxidative degradation of pollutants [7-11]. Despite being cheap, chemically robust, and generally non-toxic, $\mathrm{TiO}_{2}$ has a wide band gap of more than $3.0 \mathrm{eV}$, which means that photocatalytic processes that use $\mathrm{TiO}_{2}$ as the sensitizer can only absorb UV radiation ( $\approx 5 \%$ of the solar spectrum) $[2-4,7,8]$. Moreover, the valence band of $\mathrm{TiO}_{2}$ is strongly oxidizing whereas the conduction band level is only mildly reducing, which results in a low energy-conversion efficiency since most of the oxidation potential is wasted thermally. A number of other metal oxide semiconductors have been explored for the visible-light driven photocatalytic degradation of pollutants and microbes, such as bismuth oxides [5,6] and cerium oxides $[12,13]$. $\mathrm{CeO}_{2}$ specifically has been applied in a number of sustainable energy applications lately, including oxidative catalysis, hydrogen storage, and solar thermal dissociation of water and $\mathrm{CO}_{2}$ [14-18].

Cerium oxides with oxygen vacancies represent an underexplored area of nanotechnology with the potential to provide visible-light absorbing photocatalysts [13,19-21]. Cerium is relatively earth-abundant and the oxides, including $\mathrm{Ce}_{2} \mathrm{O}_{3}$ and $\mathrm{Ce}_{7} \mathrm{O}_{12}$, are known to have band gaps in the visible region [13,19-21]. Our team has maintained a keen interest in alternative affordable, earth-abundant, visible light absorbing metal oxides to be used in two-photon 'Z-schemes' for dye-sensitized photoelectrosynthesis cells (DSPECs) [22-24]. To be employed in DSPECs, high surface areas for dye adsorption and an efficient charge conduction are critical properties [22-24]. As part of the preliminary investigations into this field, we communicate herein the preparation of high surface area, mesoporous cerium oxide nanospheres, which is a mixed phase of $\mathrm{Ce}_{7} \mathrm{O}_{12}$ and $\mathrm{CeO}_{2}$, and can absorb visible light to photocatalytically degrade dyes such as rhodamine $\mathrm{B}(\mathrm{RhB})$. The materials characterization of the cerium oxide nanospheres and some mechanistic insights into the photocatalytic process are presented.

\section{Findings}

Polycrystalline $\mathrm{Ce}_{7} \mathrm{O}_{12}$ samples have been previously synthesized, but harsh conditions (up to $1030{ }^{\circ} \mathrm{C}$ ) by reduction of $\mathrm{CeO}_{2}$ with $\mathrm{CO}$ were employed $[25,26]$. Instead, mild, surfactant-free solvothermal conditions were used to prepare mesoporous cerium oxide with oxygen vacancies. A solution of ceric ammonium nitrate (CAN) in ethylene glycol and isopropanol as the solvent and reductant was heated up to $130{ }^{\circ} \mathrm{C}$ to yield mesoporous cerium oxide nanospheres after work-up. The powder X-ray diffraction (XRD) pattern (Figure 1a) indicates that the as-prepared cerium oxide material can be indexed to a superposition of hexagonal $\mathrm{Ce}_{7} \mathrm{O}_{12}$ (JCPDS File No. 71-0567) and cubic $\mathrm{CeO}_{2}$ (JCPDS File No. 81-0792) phases [14,26,27]. The peaks cannot be attributed to $\mathrm{Ce}(\mathrm{OH})_{3}$ or $\mathrm{Ce}_{2} \mathrm{O}_{3}$ phases $[13,28]$, and confirm that the material contains a mixed phase. The considerable broadening of the peaks suggest that the domain sizes of the nanocrystalites are small, and has been estimated to be $4.8 \mathrm{~nm}\left((211)\right.$ plane, $\left.2 \theta=28.3^{\circ}\right)$ by the Scherrer equation [29].

In order to confirm the valence states of $\mathrm{Ce}$ and quantify their relative ratios in the prepared cerium oxide, X-ray photoelectron spectroscopy (XPS) experiments with monochromatic Al $\mathrm{K} \alpha$ radiation $(h v=1486.7 \mathrm{eV})$ were conducted. Unlike $\mathrm{CeO}_{2}$, in which the $\mathrm{Ce}$ atoms are all in the oxidation state 4+, the $\mathrm{Ce}$ atoms in $\mathrm{Ce}_{7} \mathrm{O}_{12}$ consist of both $\mathrm{Ce}^{3+}$ and $\mathrm{Ce}^{4+}$ valence states. The wide-scan survey spectrum in Figure $1 \mathrm{~b}$ only shows $\mathrm{Ce} 3 \mathrm{~d}, \mathrm{O} 1 \mathrm{~s}$, and $\mathrm{C} 1 \mathrm{~s}$ signals, and no other signals. The presence of the $\mathrm{C} 1 \mathrm{~s}$ signal is probably from residual organic solvents or from air. This $\mathrm{C}$ 1s signal was used to calibrate the binding energy of the Ce $3 \mathrm{~d}$ peaks. The high-resolution spectrum of the Ce $3 \mathrm{~d}$ core states is illustrated in Figure 1c. Neither $\mathrm{Ce}^{4+}$ nor $\mathrm{Ce}^{3+}$ alone could give a satisfactory fitting to the spectrum in Figure 1c. Instead, the fitting of the Ce $3 \mathrm{~d}$ spectrum required five components derived from both $\mathrm{Ce}^{3+}$ and $\mathrm{Ce}^{4+}$. There are two components (red) from $\mathrm{Ce}^{3+}$. The principal peak is at $886.4 \mathrm{eV}$ and a $4 \mathrm{f}^{0}$ to $4 \mathrm{f}^{1} \underline{\mathrm{v}}$ ( $\underline{\mathrm{v}}$ denotes valence hole) shakedown peak is at $879.9 \mathrm{eV}$ [30]. The $\mathrm{Ce}^{4+}$ component consists of three peaks (blue). The peaks at $889.3 \mathrm{eV}$ and $883.0 \mathrm{eV}$ are the principal and $4 \mathrm{f}^{1} \underline{\mathrm{v}}$ to $4 \mathrm{f}^{2} \underline{\mathrm{v}}^{2}$ shake-down peaks from the $4 \mathrm{f}^{1} \underline{\mathrm{v}}$ electronic configuration. The highest binding energy peak at $898.7 \mathrm{eV}$ is from the $4 \mathrm{f}^{0}$ electronic configuration [30]. The binding energy of these peaks is in good agreement with those found in the literature $[19,20,31]$. However, by integrating the 
(a)

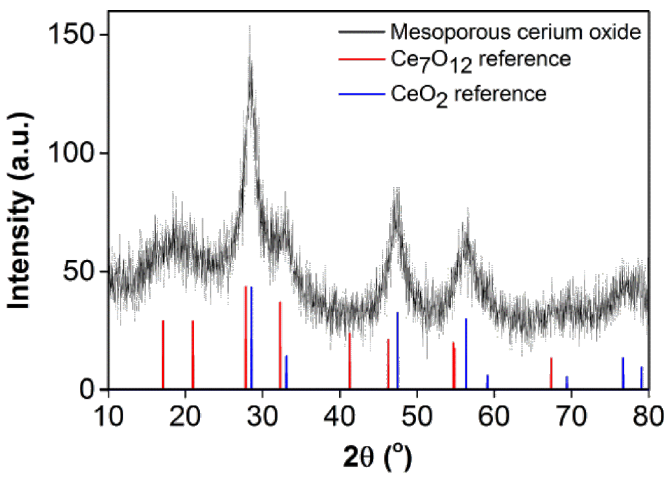

(b)

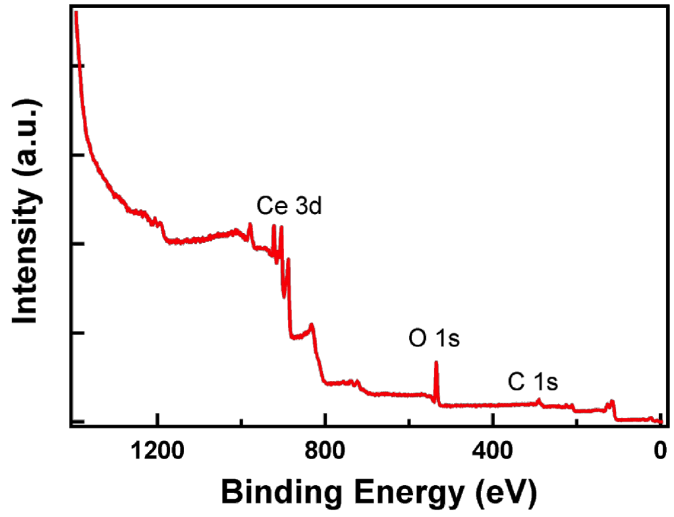

(c)

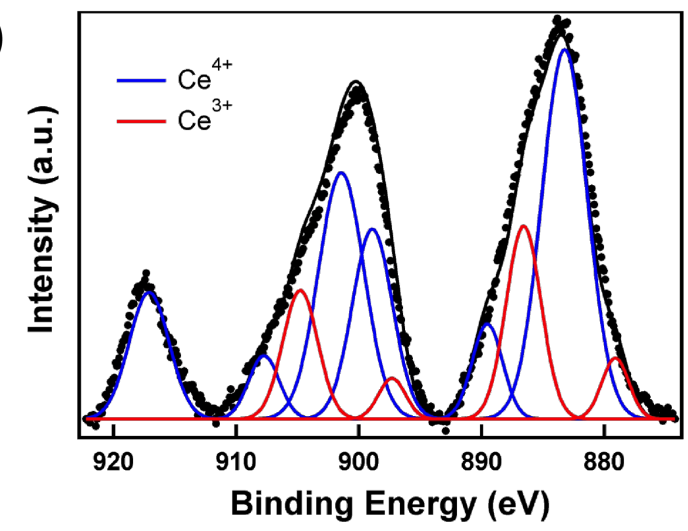

Figure 1: (a) Powder XRD pattern of cerium oxide nanospheres (b) Wide-scan XPS survey spectrum. (c) High-resolution XPS spectrum of mesoporous cerium oxide (black circles) with the overall fit (black) and the fits to $\mathrm{Ce}^{4+}$ (blue) and $\mathrm{Ce}^{3+}$ (red)

area under the fitted peaks, the concentration of $\mathrm{Ce}^{3+}$ is only $23 \%$, which deviates from the predicted stoichiometric value $(57 \%)$. This observation suggests that the $\mathrm{Ce}_{7} \mathrm{O}_{12}$ phase is mixed with some $\mathrm{CeO}_{2}$ phase on the surface. The nominal molecular formula of the material based on the XPS data is $\mathrm{CeO}_{1.89}$, comprising of around $54 \% \mathrm{Ce}_{7} \mathrm{O}_{12}$ and $46 \% \mathrm{CeO}_{2}$. The mixture of two crystalline forms is also observed in our XRD measurements and TEM results (vide infra).

The UV-vis diffuse reflectance spectra (subjected to a Kubelka-Munck transformation) of the cerium oxide nano- spheres, $\mathrm{CeO}_{2}$ (commercially available $7 \mathrm{~nm}$ ) nanopowder, and $\mathrm{TiO}_{2}$ (commercially available Degussa P25) nanoparticles are illustrated in Figure 2a. As expected, the cerium oxide sample displayed stronger visible light absorption than both commercially available $7 \mathrm{~nm} \mathrm{CeO} 2$ and $\mathrm{P} 25 \mathrm{TiO}_{2}$ nanomaterials. The estimated band gap from the Tauc plot is approximately $2.7 \mathrm{eV}$ (Figure 2b), which corresponds to an absorption edge in the blue region (460 nm). The reduced band gap compared to $\mathrm{CeO}_{2}$ can be attributed to the presence of oxygen vacancies, as previously reported [32]. The enhanced visible light absorption has been exploited for driving the photocatalytic degradation of $\mathrm{RhB}$ in aqueous solutions (vide infra).

\section{(a)}

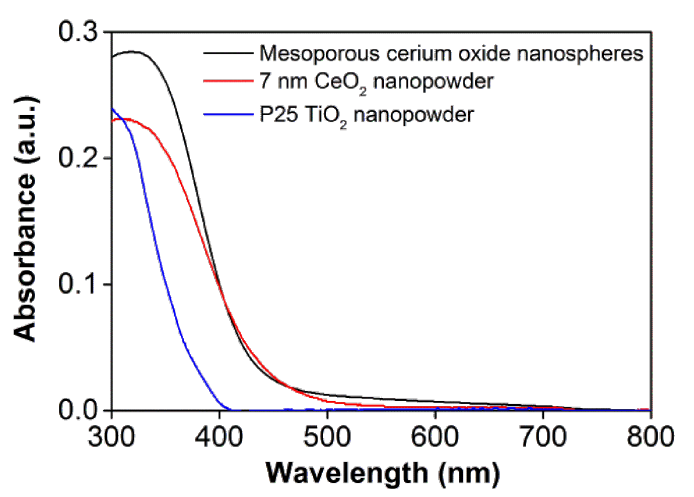

(b)

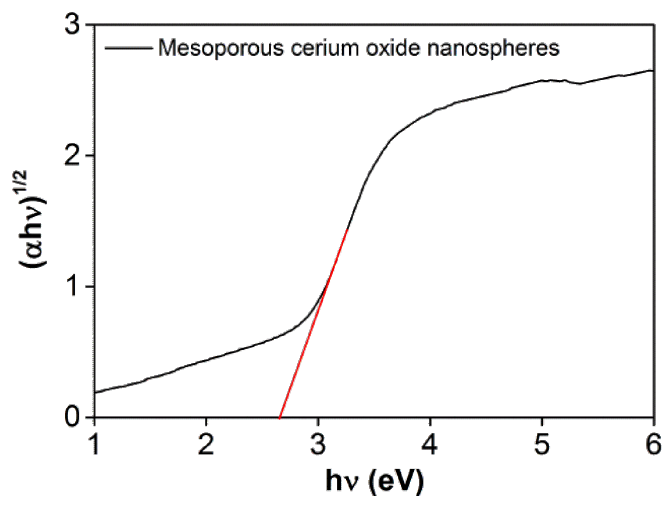

Figure 2: (a) UV-vis diffuse reflectance spectra of cerium oxide nanospheres (black), $7 \mathrm{~nm} \mathrm{CeO}$ (red) nanopowder, and $\mathrm{P}_{2} 5 \mathrm{TiO}_{2}$ (blue). (b) Tauc plot for cerium oxide to obtain the band gap.

The transmission electron microscopy (TEM) images of the cerium oxide sample supported the mesoporous nature and nanosphere morphology of the material (Figure 3a). The material has fairly monodisperse nanospheres with diameters of $50-70 \mathrm{~nm}$. Each nanosphere consists of an irregular mesoporous structure that is an aggregate of small nanocrystalline domains. The high-resolution TEM images confirm that the cerium oxide consists of crystalline domains, $4-5 \mathrm{~nm}$ in size (red dotted ring), that can be indexed to $\mathrm{Ce}_{7} \mathrm{O}_{12}$ and $\mathrm{CeO}_{2}$ (Figure 3b). Nitrogen sorption experiments were conducted to ascertain the average surface area and pore size distribution of 
(a)

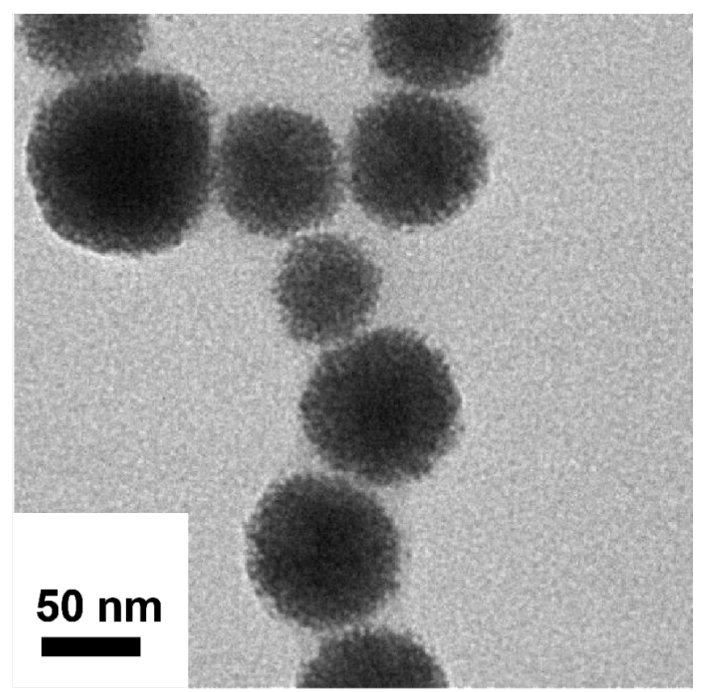

(b)

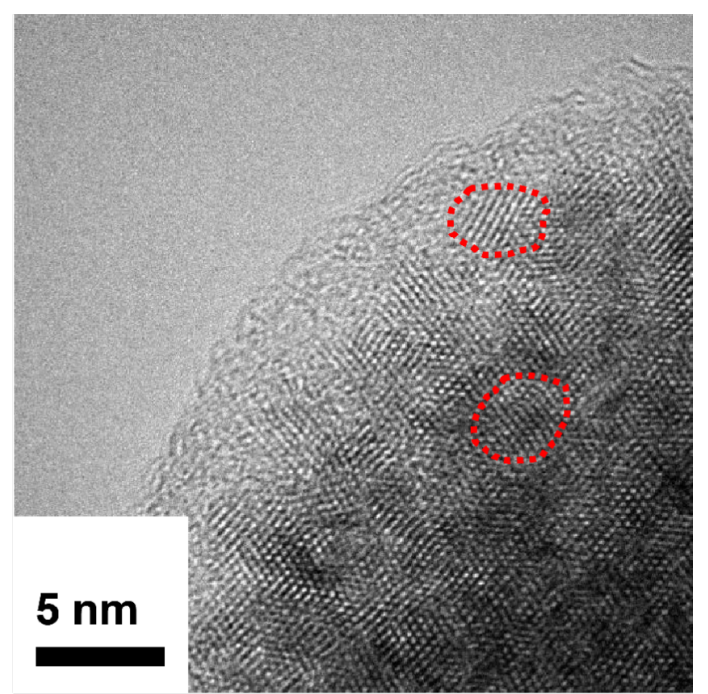

(c)

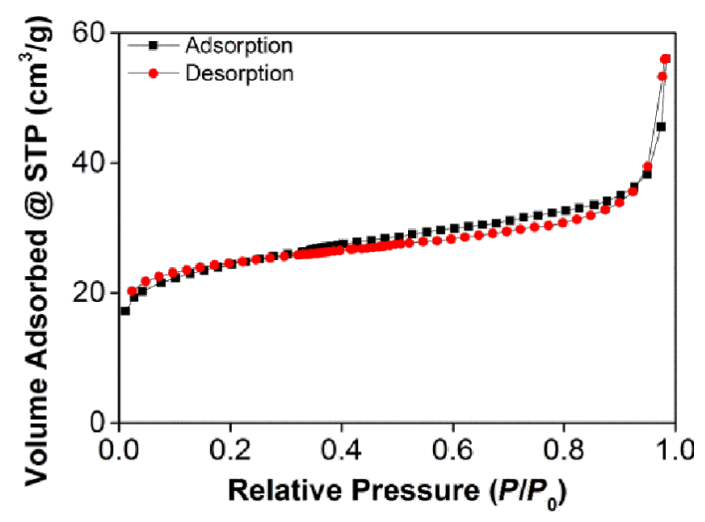

Figure 3: (a) TEM and (b) HRTEM images of the mesoporous cerium oxide nanospheres. (c) Nitrogen adsorption-desorption isotherm of the mesoporous cerium oxide nanospheres.

the material. The nitrogen adsorption-desorption isotherm of the cerium oxide sample (Figure $3 \mathrm{c}$ ) shows a type-II curve and the surface area of the sample is $93 \mathrm{~m}^{2} \mathrm{~g}^{-1}$ as calculated by the
Brunauer-Emmett-Teller (BET) method. The average pore size determined by a Barrett-Joyner-Halenda (BJH) analysis is $3 \mathrm{~nm}$, confirming the mesoporous nature of the cerium oxide sample.

The photocatalytic behavior at visible-light irradiation of the cerium oxide sample has been probed by the photodegradation of the suspected carcinogenic dye rhodamine B (RhB). A colloidal mixture of cerium oxide and $\mathrm{RhB}$ has been stirred and irradiated with AM 1.5 solar intensity light after equilibration in the dark for $30 \mathrm{~min}$. A standard glass filter has been applied to transmit only wavelengths larger than $420 \mathrm{~nm}$, to demonstrate photocatalytic properties under ambient conditions. The UV-vis spectral changes of the colloidal mixture illustrated in Figure 4 clearly shows the degradation of RhB over time, with the dye being completely decomposed within $6 \mathrm{~h}$. In comparison, RhB is only decomposed to $50 \%$ or less after irradiation under the same conditions with the commercially available $\mathrm{P} 25 \mathrm{TiO}_{2}$ and $7 \mathrm{~nm} \mathrm{CeO} 2$ nanopowder. The visible-light photocatalytic degradation of organic compounds with wide band-gap materials, by a ligand-to-metal charge-transfer mechanism after adsorption [33], has been reported and may be a contributing factor for the activity of $\mathrm{TiO}_{2}$ and $\mathrm{CeO}_{2}$. In the absence of light, some of the RhB adsorbs on the cerium oxide (green). The mesoporous cerium oxide sample is patently a more effective agent for the photocatalytic degradation of RhB under visible light and ambient conditions after equilibration, and the activity cannot be accounted to the presence of $\mathrm{CeO}_{2}$ or adsorption alone. Gas chromatography mass spectrometry (GC-MS) and electrospray ionisation mass spectrometry (ESI-MS) were used to identify some of the organic products during the course of the $6 \mathrm{~h}$ irradiation (see Supporting Information File 1). These included $N$-hydroxylated desethyl rhodamine B, phthalic acid, and even

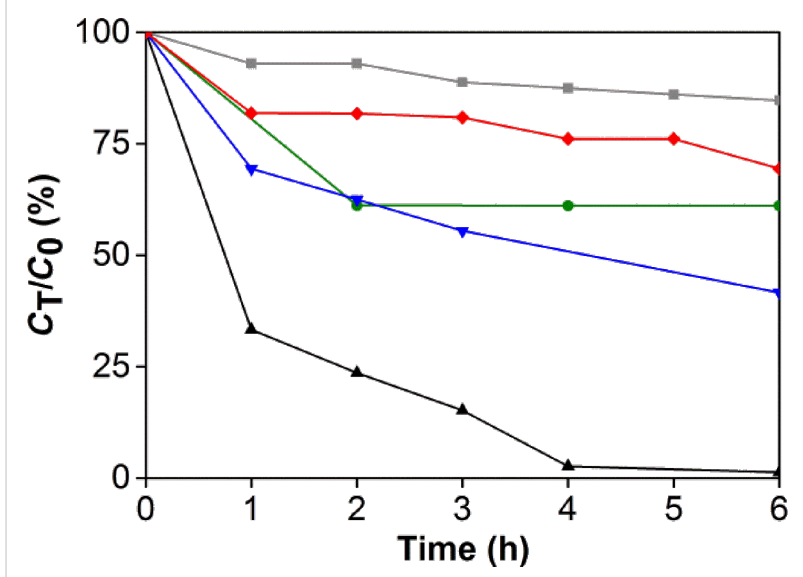

Figure 4: Comparison of RhB concentrations over time at $554 \mathrm{~nm}$, after photocatalytic degradation with mesoporous cerium oxide under light (black) and in the dark with no equilibration (green), $7 \mathrm{~nm} \mathrm{CeO} 2$ (red), P25 $\mathrm{TiO}_{2}$ (blue), and with no catalyst (grey). 
ring-opened products [6]. The composition of the degradation products alludes to oxidative decomposition by reactive oxygen species, such as hydroxyl radicals.

Chemical scavengers were employed to investigate the mechanism of the photocatalytic processes and to identify the major contributors to the photocatalytic processes. The concentration of $\mathrm{RhB}$, monitored at $554 \mathrm{~nm}$, was used as the proxy to identify the active agent in the decomposition of RhB. Control experiments were performed in the absence of scavengers (black line, Figure 5a). The established scavengers used include sodium oxalate for $h^{+}$(red), $\mathrm{CrO}_{3}$ for $e^{-}$(green), isopropanol for ${ }^{\circ} \mathrm{OH}$
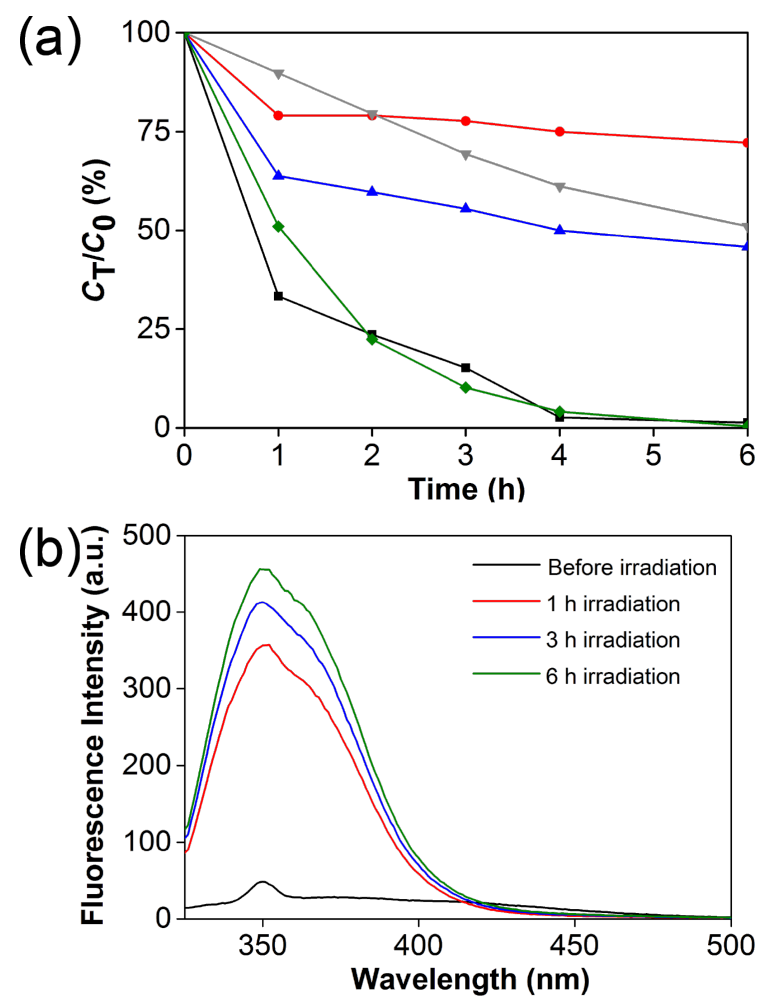

(c)

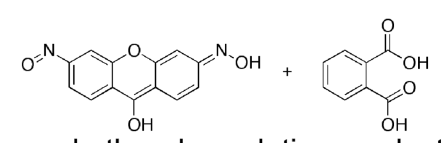
and other degradation products

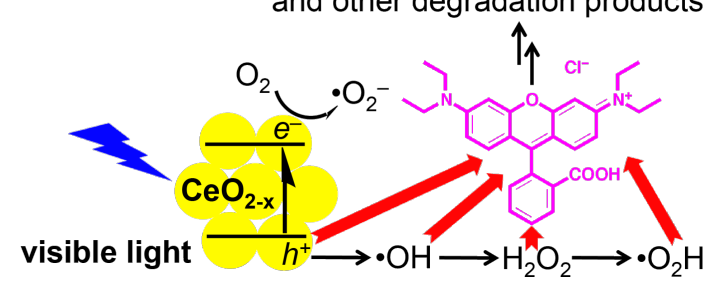

Figure 5: (a) Photocatalytic degradation of RhB over time at $554 \mathrm{~nm}$, in the absence of scavengers (black), and the presence of $h^{+}$(red), $\cdot \mathrm{OH}$ (blue), $e^{-}$(green), and ${ }^{\circ} \mathrm{OOH} /{ }^{\circ} \mathrm{O}_{2}^{-}$scavengers (grey). (b) Growth of the fluorescence intensity of 2-hydroxyterephthlate as a probe for hydroxyl radicals. (c) Proposed pathway for photocatalytic RhB degradation. (blue), and 1,4-benzoquinone for ${ }^{\circ} \mathrm{OOH} /{ }^{\circ} \mathrm{O}_{2}{ }^{-}$(grey, Figure 5a) [5]. The inhibition of photocatalytic activity is most pronounced in the presence of the hole scavenger, with impaired activity in the presence of both ${ }^{\circ} \mathrm{OH}$ and ${ }^{\circ} \mathrm{OOH} /{ }^{\bullet} \mathrm{O}_{2}{ }^{-}$scavengers. Interestingly, the electron scavenger does not significantly affect the photodegradation experiments. The participation of ${ }^{\circ} \mathrm{OH}$ radicals was confirmed with the use of sodium terephthalate as a fluorescence probe [34]. Over the course of $6 \mathrm{~h}$, the fluorescence intensity due to formation of 2-hydroxyterephthalate grew [35], with a blue shift possibly due to coordination to the mesoporous cerium oxide nanoparticles (Figure 5b). These results indicate that the photocatalytic mechanism can be summarized as depicted in Figure 5c, in which $h^{+}$, and downstream reactive oxygen species ${ }^{\circ} \mathrm{OH}$ and ${ }^{\circ} \mathrm{OOH} /{ }^{\circ} \mathrm{O}_{2}{ }^{-}$, are the active agents for the chemical destruction of $\mathrm{RhB}$. Superoxide radicals from the reduction of $\mathrm{O}_{2}$ or direct reduction by electrons from the cerium oxide appear to play secondary roles in the photocatalytic destruction of RhB.

\section{Conclusion}

In summary, we have presented a facile, solvothermal synthesis of new mesoporous cerium oxide nanospheres, with isopropanol and ethylene glycol as the solvents and reducing agents. No expensive surfactants and templates have been used in the preparation of the earth-abundant, relatively affordable, mixed valence cerium oxide. The cerium oxide has been characterized with a suite of structural, spectroscopic, and electron microscopy techniques, confirming the high surface area, mesoporous nature, and visible-light absorption properties of the material. The visible-light photocatalytic activity in the degradation of $\mathrm{RhB}$ surpasses that of the commercially available $\mathrm{CeO}_{2}$ and $\mathrm{P} 25 \mathrm{TiO}_{2}$ nanopowders. With a series of radical scavengers, the mechanism of the photocatalytic activity is proposed to involve a prominent role of ${ }^{\bullet} \mathrm{OH}$ radicals as the active species in $\mathrm{RhB}$ degradation. This new material is a promising candidate as a robust, earth-abundant, visible-light absorbing metal oxide scaffold to be used in DSPECs and other sustainable energy applications.

\section{Supporting Information}

The Supporting Information provides details about the synthesis of the nanospheres as well as additional experimental data.

\section{Supporting Information File 1}

Synthesis procedure, characterization, and dye degradation studies.

[http://www.beilstein-journals.org/bjnano/content/ supplementary/2190-4286-5-60-S1.pdf] 


\section{Acknowledgements}

H. S. Soo is supported by a NTU start-up grant (M4081012) and the Nanyang Assistant Professorship (M4081154). T. C. Sum is supported by a NTU start-up grant (M4080514), and the SPMS collaborative Research Award (M4080536). H. S. Soo and T. C. Sum also acknowledge the funding support from the Singapore-Berkeley Research Initiative for Sustainable Energy (SinBeRISE) CREATE Programme. This research programme/ project is funded by the National Research Foundation (NRF), Prime Minister's Office, Singapore under its Campus for Research Excellence and Technological Enterprise (CREATE) programme. S.K. Muduli and H.S. Soo thank Nanyang Asst. Prof. Ling Xing Yi for the use of her solar simulator, and Nanyang Asst. Prof. Zhao Yanli for the use of his gas sorption analyzer. The authors also thank Dr. Wei Fengxia for her assistance with HRTEM measurements and Dr. Sarifuddin Gazi for his help with EPR experiments.

\section{References}

1. Andreozzi, R.; Caprio, V.; Insola, A.; Marotta, R. Catal. Today 1999, 53, 51-59. doi:10.1016/S0920-5861(99)00102-9

2. Hoffmann, M. R.; Martin, S. T.; Choi, W.; Bahnemann, D. W. Chem. Rev. 1995, 95, 69-96. doi:10.1021/cr00033a004

3. Chalasani, R.; Vasudevan, S. ACS Nano 2013, 7, 4093-4104. doi:10.1021/nn400287k

4. Kisch, H. Angew. Chem., Int. Ed. 2013, 52, 812-847. doi:10.1002/anie.201201200

5. Wang, W.; Yu, Y.; An, T.; Li, G.; Yip, H. Y.; Yu, J. C.; Wong, P. K. Environ. Sci. Technol. 2012, 46, 4599-4606. doi:10.1021/es2042977

6. Yu, K.; Yang, S.; He, H.; Sun, C.; Gu, C.; Ju, Y. J. Phys. Chem. A 2009, 113, 10024-10032. doi:10.1021/jp905173e

7. Chen, H.; Nanayakkara, C. E.; Grassian, V. H. Chem. Rev. 2012, 112, 5919-5948. doi:10.1021/cr3002092

8. Chen, X.; Mao, S. S. Chem. Rev. 2007, 107, 2891-2959. doi:10.1021/cr0500535

9. Hagfeldt, A.; Boschloo, G.; Sun, L.; Kloo, L.; Pettersson, H. Chem. Rev. 2010, 110, 6595-6663. doi:10.1021/cr900356p

10. Hodes, G.; Cahen, D. Acc. Chem. Res. 2012, 45, 705-713. doi:10.1021/ar200219h

11. Kubacka, A.; Fernández-García, M.; Colón, G. Chem. Rev. 2012, 112, 1555-1614. doi:10.1021/cr100454n

12. Pouretedal, H. R.; Kadkhodaie, A. Chin. J. Catal. 2010, 31, 1328-1334. doi:10.1016/S1872-2067(10)60121-0

13. Vuppala, V.; Motappa, M. G.; Venkata, S. S.; Sadashivaiah, P. H. Eur. J. Chem. 2012, 3, 191-195. doi:10.5155/eurjchem.3.2.191-195.564

14. Chueh, W. C.; Falter, C.; Abbott, M.; Scipio, D.; Furler, P.; Haile, S. M.; Steinfeld, A. Science 2010, 330, 1797-1801. doi:10.1126/science.1197834

15. Chueh, W. C.; Haile, S. M. ChemSusChem 2009, 2, 735-739. doi:10.1002/cssc.200900138

16. Scheffe, J. R.; Steinfeld, A. Energy Fuels 2012, 26, 1928-1936. doi:10.1021/ef201875v

17.Zhang, D.; Du, X.; Shi, L.; Gao, R. Dalton Trans. 2012, 41, 14455-14475. doi:10.1039/c2dt31759a
18. Muhich, C. L.; Evanko, B. W.; Weston, K. C.; Lichty, P.; Liang, X.; Martinek, J.; Musgrave, C. B.; Weimer, A. W. Science 2013, 341, 540-542. doi:10.1126/science.1239454

19. Ghoshal, T.; Fleming, P. G.; Holmes, J. D.; Morris, M. A. J. Mater. Chem. 2012, 22, 22949-22957. doi:10.1039/c2jm35073d

20. Stetsovych, V.; Pagliuca, F.; Dvořák, F.; Duchoň, T.; Vorokhta, M.; Aulická, M.; Lachnitt, J.; Schernich, S.; Matolinová, I.; Veltruská, K.; Skála, T.; Mazur, D.; Mysliveček, J.; Libuda, J.; Matolín, V. J. Phys. Chem. Lett. 2013, 4, 866-871. doi:10.1021/jz400187j

21. Wilkens, H.; Schuckmann, O.; Oelke, R.; Gevers, S.; Schaefer, A.; Bäumer, M.; Zoellner, M. H.; Schroeder, T.; Wollschläger, J. Appl. Phys. Lett. 2013, 102, 111602. doi:10.1063/1.4795867

22. Luo, H.; Song, W.; Hoertz, P. G.; Hanson, K.; Ghosh, R.; Rangan, S.; Brennaman, M. K.; Concepcion, J. J.; Binstead, R. A.; Bartynski, R. A.; Lopez, R.; Meyer, T. J. Chem. Mater. 2013, 25, 122-131. doi:10.1021/cm3027972

23. Song, W.; Chen, Z.; Glasson, C. R. K.; Hanson, K.; Luo, H.; Norris, M. R.; Ashford, D. L.; Concepcion, J. J.; Brennaman, M. K.; Meyer, T. J. ChemPhysChem 2012, 13, 2882-2890. doi:10.1002/cphc. 201200100

24. Alibabaei, L.; Luo, H.; House, R. L.; Hoertz, P. G.; Lopez, R.; Meyer, T. J. J. Mater. Chem. A 2013, 1, 4133-4145. doi:10.1039/c2ta00935h

25. Ray, S. P.; Cox, D. E. J. Solid State Chem. 1975, 15, 333-343. doi:10.1016/0022-4596(75)90289-3

26. Kümmerle, E. A.; Heger, G. J. Solid State Chem. 1999, 147, 485-500. doi:10.1006/jssc.1999.8403

27. Ray, S. P.; Nowick, A. S.; Cox, D. E. J. Solid State Chem. 1975, 15 , 344-351. doi:10.1016/0022-4596(75)90290-X

28. Suresh, R.; Ponnuswamy, V.; Mariappan, R. Appl. Surf. Sci. 2013, 273, 457-464. doi:10.1016/j.apsusc.2013.02.062

29. Patterson, A. L. Phys. Rev. 1939, 56, 978-982. doi:10.1103/PhysRev.56.978

30. Kotani, A.; Ogasawara, H. J. Electron Spectrosc. Relat. Phenom. 1992, 60, 257-299. doi:10.1016/0368-2048(92)80024-3

31. Trudeau, M. L.; Tschöpe, A.; Ying, J. Y. Surf. Interface Anal. 1995, 23 , 219-226. doi:10.1002/sia.740230405

32. Corma, A.; Atienzar, P.; Garcia, H.; Chane-Ching, J.-Y. Nat. Mater. 2004, 3, 394-397. doi:10.1038/nmat1129

33. Liang, S.; Wen, L.; Lin, S.; Bi, J.; Feng, P.; Fu, X.; Wu, L. Angew. Chem., Int. Ed. 2014, 53, 2951-2955. doi:10.1002/anie.201311280

34. Gomes, A.; Fernandes, E.; Lima, J. L. F. C. J. Biochem. Biophys. Methods 2005, 65, 45-80. doi:10.1016/j.jbbm.2005.10.003

35. Ishibashi, K.; Fujishima, A.; Watanabe, T.; Hashimoto, K. J. Photochem. Photobiol., A: Chem. 2000, 134, 139-142. doi:10.1016/S1010-6030(00)00264-1 


\section{License and Terms}

This is an Open Access article under the terms of the Creative Commons Attribution License

(http://creativecommons.org/licenses/by/2.0), which permits unrestricted use, distribution, and reproduction in any medium, provided the original work is properly cited.

The license is subject to the Beilstein Journal of Nanotechnology terms and conditions:

(http://www.beilstein-journals.org/bjnano)

The definitive version of this article is the electronic one which can be found at:

doi:10.3762/bjnano.5.60 